\title{
Short communication: Meta-analysis of dairy cows fed conventional sorghum or corn silages compared with brown midrib sorghum silage
}

\author{
J. I. Sánchez-Duarte, ${ }^{1 *}$ K. F. Kalscheur, ${ }^{2} \dagger$ A. D. García, ${ }^{1}$ and F. E. Contreras-Govea ${ }^{3}$ \\ ${ }^{1}$ Dairy and Food Science Department, South Dakota State University, Brookings 57007 \\ ${ }^{2}$ US Dairy Forage Research Center, USDA-Agricultural Research Service, Madison, WI 53706 \\ ${ }^{3}$ Department of Dairy Science, University of Wisconsin, Madison 53706
}

\section{ABSTRACT}

A meta-analysis was conducted to compare the effects of feeding dairy cows conventional sorghum silage (CSS) or conventional corn silage (CCS) compared with brown midrib sorghum silage (BMRSS) diets on dry matter intake (DMI), milk production, and milk composition. Data from 9 published articles (1984 to 2015) were used to contrast diets with CSS (7 means comparisons; 104 cows) or CCS (13 means comparisons; 204 cows) versus BMRSS diets. Statistical analysis was performed using fixed or random effects models with the Metafor package of R (https://www.R-project.org). The degree of heterogeneity was measured with the $I^{2}$ statistic, and publication bias was determined with funnel plots and Egger's regression test. Other sources of heterogeneity of response were analyzed through metaregression. Estimated effect size was calculated for DMI, milk production, and milk composition. No evidence of publication bias was observed for any variable tested. The highest degree of heterogeneity $\left(I^{2}=41.5\right.$ and $72.6 \%$ ) was observed for DMI among dependent variables tested in both comparisons, indicating that intake responses to silage type are rather inconsistent; in contrast, milk production had the lowest degree of heterogeneity $\left(I^{2}=0 \%\right)$, supporting the idea that the responses of this variable to silage type were very consistent across studies. Compared with BMRSS diets, cows fed CSS diets exhibited decreased milk production $(1.64 \mathrm{~kg} / \mathrm{d})$, milk fat concentration $(0.09 \%)$, milk fat yield $(0.08 \mathrm{~kg} / \mathrm{d})$, milk protein yield $(0.04 \mathrm{~kg} / \mathrm{d})$, and milk lactose yield $(0.16 \mathrm{~kg} / \mathrm{d})$ and tended to decrease DMI $(0.83 \mathrm{~kg} / \mathrm{d})$. Compared with CCS diets, cows fed BMRSS diets increased milk fat concentration $(0.10 \%)$, but decreased milk protein concentration $(0.06 \%)$ and

Received February 6, 2018.

Accepted September 20, 2018.

*Present address: Instituto Nacional de Investigaciones Forestales Agrícolas y Pecuarias, Matamoros, Coahuila, México 27440.

†Corresponding author: kenneth.kalscheur@ars.usda.gov tended to increase lactose yield $(0.08 \mathrm{~kg} / \mathrm{d})$. Metaregression indicated that days in milk affected DMI and milk production when CSS diets were compared with BMRSS diets, and DMI when CCS diets were compared with BMRSS diets. Additionally, the inclusion rate of silage in the diet and dietary neutral detergent fiber affected yields of milk fat and lactose, respectively, when CCS and BMRSS diets were compared. Overall, lactation performance improved when cows were fed diets formulated with BMRSS compared with CSS, but performance was not different for cows fed BMRSS and CCS diets. However, the small sample size may have influenced these results by increasing the margin of the error and, concurrently, the power of the meta-analysis. Results of this analysis suggest that additional research is needed to explore the effects of days in milk and the inclusion rates of silages in the diets when comparing BMRSS with CSS or CCS.

Key words: milk production, milk composition, Sorghum bicolor L., sorghum silage

\section{Short Communication}

Sorghum silage is a viable forage alternative for dairy farms in areas with reduced rainfall because sorghum is tolerant to low soil moisture conditions (Peacock, 1982; Jahanzad et al., 2013) while still producing adequate DM tonnage per hectare (Blum et al., 1989). However, the lignin content in late vegetative and early head stages of conventional sorghum plants can be quite high $(53.1 \mathrm{~g} / \mathrm{kg}$ of DM). As a result, the NDF digestibility of the resulting sorghum silage is decreased (Miron et al., 2005), which may negatively affect the production response when fed to dairy cows. Brown midrib (BMR) sorghum hybrids, on the other hand, can be a viable alternative because they contain less lignin at a similar stage of maturity $(43.7 \mathrm{~g} / \mathrm{kg}$ of DM; Miron et al., 2005), which improves the NDF digestibility of the silage (Bucholtz et al., 1980). The higher digestibility of BMR sorghum hybrids could prove advantageous, considering they have traditionally yielded less forage DM per hectare compared with conventional sorghum 
or corn hybrids (Bean and McCollum, 2006; Bean et al., 2007, 2010; Marsalis et al., 2010).

The inclusion of BMR sorghum silage (BMRSS) in diets of dairy cows may result in increased fiber digestion, which can improve energy consumption and animal performance. Kinetics of forage fiber digestion have demonstrated similar extent of NDF digestibility in vitro between BMRSS and conventional sorghum silage (CSS) diets (Aydin et al., 1999). However, when NDF digestion was measured in situ, the extent of NDF digestion was similar between BMRSS and conventional corn silage (CCS) diets, but lower in CSS diets (Grant et al., 1995). Those differences resulted later in greater milk production for dairy cows fed BMRSS diets than cows fed CSS diets, but similar between cows fed BMRSS and CCS diets (Aydin et al., 1999). In spite of the differences in fiber digestion and cow performance between silage types, DMI was similar, indicating a notable inconsistency in the studies. Results have also varied between studies regarding milk composition, but the most noticeable discrepancy occurred with milk fat and protein concentrations. For example, when 2 types of BMRSS diets were compared with a CSS diet, milk fat percentage and yield were similar in one comparison but greater for cows fed the BMRSS diet in the second comparison (Oliver et al., 2004). In contrast, when 2 inclusion rates of both CCS and BMRSS (35 and 45\% of DM; Dann et al., 2008) were contrasted, milk protein percentage was similar when $35 \%$ of either silage type was included. However, at $45 \%$ inclusion in the diet, milk protein percentage was greater for cows fed CCS diets compared with those fed BMRSS diets.

Therefore, a meta-analysis of all productive responses would likely identify the overall effect of adding CSS or CCS and BMRSS to lactating dairy cow diets. The objective of this study was to use a meta-analysis to compare the effects of silage type (CSS, CCS, or BMRSS) on DMI, milk production, and milk composition in dairy cows.

For a highly comprehensive publication search, all information was obtained from PubMed, Web of Science, and Agricola-USDA using the keywords "sorghum silage," "sorghum BMR," "Brown Midrib sorghum," and the combination of the previous words with "dairy cows." Once papers regarding this study were identified, specific published papers cited in their references section were recognized and then searched directly in the journals or on the web. Studies included had to contrast the effect of feeding CSS or CCS diets and BMRSS diets and treatments had to completely replace conventional varieties of CSS or CCS with BMRSS in the diets. Required criteria for selected studies included clearly reported information on DMI, milk production, and milk composition, including standard error of the mean (SE) or standard deviation (SD) and $P$-values for treatment comparisons. A total of 9 papers published between 1984 and 2015 were included in the metaanalysis (Supplemental Table S1; https://doi.org/10 $.3168 /$ jds.2018-14552), of which 5 (2 papers with multiple comparisons and 3 papers with single comparisons, resulting in 7 comparisons total; 104 cows) were used to contrast CSS and BMRSS diets (Grant et al., 1995; Aydin et al., 1999; Oliver et al., 2004; Miron et al., 2007; Astigarraga et al., 2014), and 8 (5 papers with multiple comparisons and 3 papers with single comparisons, resulting in 13 comparisons total; 204 cows) were included to compare CCS and BMRSS diets (Lusk et al., 1984; Grant et al., 1995; Aydin et al., 1999; Oliver et al., 2004; Miron et al., 2007; Dann et al., 2008; Colombini et al., 2010; Bernard and Tao, 2015). Therefore, papers from Grant et al. (1995), Aydin et al. (1999), Oliver et al. (2004), and Miron et al. (2007) were used in both comparisons.

The variables evaluated were DMI, milk production, milk component (fat, protein, and lactose) percentages, and milk component yields. The data set included mean, standard deviation, and number of cows per treatment. Descriptive statistics of the evaluated variables comparing silage type are given in Supplemental Table S2 (https://doi.org/10.3168/jds.2018-14552). The precision of the estimate was based on the reported standard error or standard deviation in the treatments with CSS or CCS diets versus BMRSS diets. When those statistical estimates were not reported, they were calculated from their $P$-values; if a $P<0.05$ was indicated, then 0.05 was used for the calculation.

The effect of feeding different silages on production response of lactating dairy cows was evaluated through a meta-analysis using the fixed and random effect models with the Metafor package (Viechtbauer, 2010) in R (R Core Team, 2015). Each variable was first analyzed by the fixed-effects model to estimate the effect size (ES), 95\% CI, and the statistical significance of the ES. Heterogeneity in experiment-level ES was assessed with the Q statistic test (Huedo-Medina et al., 2006). The analysis of estimated ES was calculated with standardized Z-statistic. If the Q test was significant, a random-effects model was used (Lean et al., 2009). The meta-analysis was adapted to a random-effect model (Overton, 1998) because the Q test indicated heterogeneity among ES for all variables $(P<0.05)$.

The degree of total variability of ES for the variables was evaluated with the $I^{2}$ statistic (Higgins and Thompson, 2002). Values of $I^{2}$ around 25, 50, and 75\% would indicate low, medium, and high heterogeneity, respectively (Higgins and Thompson, 2002). All outcomes of the variables that weighted mean differences of CSS or CCS diets relative to BMRSS diets were 
calculated to show the specific values of the effects of feeding the different silages on the productive responses of lactating dairy cows. Statistical significance was set at $P \leq 0.05$ and trend effects when $0.05<P \leq 0.10$.

The effects of feeding different silages on the productive response of dairy cows were displayed in forest plots (DistillerSR Forest Plot Generator from Evidence Partners; https://www.evidencepartners.com/resources/ forest-plot-generator/), using the standardized mean difference (SMD) of each variable according to the random-effect model. Information displayed in forest plots also provided the means and 95\% CI for primary studies. The weight of each study was calculated by the inverse of the variance of ES. The SMD was calculated by dividing the mean difference in each study by the standard deviation of one or both populations to report the difference across studies as an index (Lean et al., 2009). The SMD of each productive variable between CSS or CCS diets and BMRSS diets was the outcome of interest displayed in the forest plot.

The presence of publication bias was tested using contour-enhanced funnel plots. A funnel plot is a simple scatterplot of the treatment inversion effect estimated from individual studies (horizontal axis) against a measure of study size (vertical axis; Sterne and Harbord, 2004). In addition, the asymmetry of the funnel plot was evaluated with the regression test proposed by Egger et al. (1997), which uses the actual values and the precision of ES.

Meta-regression analysis was used to identify any other sources of undetected heterogeneity and to provide greater insight and a clearer interpretation of how the study outcomes are not affected by factors other than the silage effects. The variables for the meta-regression were DIM, parity, inclusion of silage and forage in the diet, and dietary CP and NDF. A factor was considered to affect heterogeneity of the variable under evaluation when $P \leq 0.05$.

In general, NDF and ADF concentrations were 1.9 and 2.4 percentage units higher in CSS than in BMRSS, respectively, and the lignin concentration was 1.9 percentage units lower in BMRSS compared with CSS (Supplemental Table S3; https://doi.org/10.3168/ jds.2018-14552). Therefore, CSS presented lower NDF digestibility (50.8\% NDF) than BMRSS (58.2\% NDF). When CCS was compared with BMRSS, we observed lower percentage unit values of NDF (4), ADF (7.9), and lignin (1.7) in CCS than in BMRSS. Even with those differences in fiber and lignin concentration between silages, BMRSS had greater NDF digestibility ( $55.1 \%$ NDF) than CCS (53.2\% NDF).

The inclusion rate of the silages in the diets was similar in both comparisons, indicating that the replacement of conventional varieties of sorghum or corn with BMRSS was in a proportion of 1:1 (Supplemental Table S4; https://doi.org/10.3168/jds.2018-14552). The main nutrient composition difference among diets was the NDF concentration, which was slightly higher in CSS diets $(38.46 \%)$ than in BMRSS diets $(37.7 \%)$, but lower in CCS diets (34.9\%) compared with BMRSS diets $(36.7 \%)$. Those alterations of fiber concentration in the diets were due to differences in NDF content of the silage types.

Overall, funnel plots did not show any marked asymmetry, which indicated no publication bias for DMI, milk production, or milk composition data comparing CSS or CCS diets with BMRSS diets (Supplemental Figures S1 and S2; https://doi.org/10.3168/jds.2018 -14552). Egger's regression test to assess the asymmetry of all funnel plots confirmed that all productive variables were not skewed $(P>0.05$; Table 1$)$. Nevertheless, the assessment of publication bias with funnel plots with such a small number of studies as used here requires caution because the power of the test could be too low to detect real asymmetry (Terrin et al., 2005).

Meta-analytic comparison between cows fed CSS and BMRSS diets (Table 1) showed that cows on CSS diets tended to decrease DMI $(0.83 \mathrm{~kg} / \mathrm{d}$; ES $=-0.31, P=$ $0.09)$ and significantly decreased milk production (1.64 $\mathrm{kg} / \mathrm{d} ; \mathrm{ES}=-0.83, P<0.001)$, milk fat percentage $(0.09$ units; $\mathrm{ES}=-0.34, P=0.03)$, milk fat yield $(0.08$ $\mathrm{kg} / \mathrm{d} ; \mathrm{ES}=-0.77, P<0.001)$, milk protein yield $(0.04$ $\mathrm{kg} / \mathrm{d} ; \mathrm{ES}=-0.63, P<0.001)$, and milk lactose yield $(0.16 \mathrm{~kg} / \mathrm{d} ; \mathrm{ES}=0.36, P=0.02)$. No significant effects were observed between the CSS and BMRSS diets for milk protein and milk lactose percentages. The $I^{2}$ statistic indicated only moderate heterogeneity for DMI $(41.5 \%)$ and milk protein yield $(29.9 \%)$ and negligible heterogeneity for the other variables (0 to $2 \%$ ).

The meta-analysis demonstrated that milk fat percentage decreased 0.10 units $(\mathrm{ES}=-0.34, P=0.009)$ in cows fed CCS diets relative to those fed BMRSS diets (Table 1); however, milk protein percentage increased 0.06 units $(\mathrm{ES}=0.44, P=0.003)$ in cows fed CCS diets. No effects were found among silages for DMI, milk production, milk fat yield, milk protein yield, or milk lactose percentage, but a positive trend was detected in cows fed CCS diets compared with BMRSS diets for milk lactose yield $0.08 \mathrm{~kg} / \mathrm{d}(\mathrm{ES}=0.26, P=0.07)$. Substantial heterogeneity $\left(I^{2}>50 \%\right)$ was observed for DMI, protein yield, and lactose percentage; but heterogeneity was unimportant for milk production and milk fat percentage $\left(I^{2}=0\right.$ to $\left.12 \%\right)$ and moderate $\left(I^{2}=19\right.$ to $40 \%$ ) for milk fat yield, milk protein percentage, and milk lactose yield.

Forest plots showed greater variation for DMI (Figure 1) than milk production (Supplemental Figures S3A and S4A; https://doi.org/10.3168/jds.2018-14552) 
Table 1. Estimated effect size derived from meta-analysis for lactating dairy cows fed different silages ${ }^{1}$



${ }^{1} \mathrm{CSS}=$ conventional sorghum silage, $\mathrm{CCS}=$ conventional corn silage, BMRSS $=$ brown midrib sorghum silage.

${ }^{2}$ Weighted mean difference is an estimate of actual effects for cows fed different silages in units measured.

${ }^{3} I^{2}$ is a measure of variation beyond chance among studies used in the meta-analysis.

in either comparison, which was already supported by the highest heterogeneity values for DMI in Table $1\left(I^{2}\right.$ $=41.5 \%$ and $72.6 \%$ ). Additional forest plots for milk components are shown in Supplemental Figures S3 and S4 (https://doi.org/10.3168/jds.2018-14552). These plots support the statistical power provided by the studies to produce a more precise overall estimate of the positive or negative effects on production response in cows fed different silages.

Reductions in fiber digestion, decreases in passage rate, and increases in rumen fill resulting in decreased DMI are some factors associated with lower NDF digestibility (Oba and Allen, 1999). Brown midrib forage sorghum hybrids can contain from 0.1 to $0.8 \%$ less lignin than conventional forage sorghum and corn hybrids (Miller and Stroup, 2003). Such lignin differences among these crops have resulted in higher in situ NDF digestion rates in BMRSS $\left(0.037 \mathrm{~h}^{-1}\right)$ and CCS $(0.036 \mathrm{~h}$ $\left.{ }^{-1}\right)$ than in CSS $\left(0.023 \mathrm{~h}^{-1}\right)$. Lower NDF digestibility of CSS relative to BMRSS would decrease DMI of lactating dairy cows (Oba and Allen, 1999; Mertens, 2009; Jung et al., 2011). In addition, in vivo apparent totaltract NDF digestibility was greater in BMRSS (54.4\%) compared with CSS diets (40.8\%), but similar to CCS diets (54.1\%; Oliver et al., 2004). It is likely that differences in fiber digestibility reported in particular studies and confirmed in this meta-analysis are associated with DMI differences observed between silages.

The milk production results of the current metaanalysis could be explained by the decrease in DMI when BMRSS replaced CSS in the diet, and the similar DMI between CCS and BMRSS diets. A recent metaanalysis reported that an increase in milk production was associated with greater DMI, which resulted from improved in vitro or in situ forage NDF digestibility (Sousa et al., 2016). The forages used in these trials were alfalfa, grass, CCS, BMRSS, and CSS. When forages were analyzed together, DMI and milk production increased 0.07 and $0.08 \mathrm{~kg} / \mathrm{d}$, respectively, per unit of increased forage NDF digestibility. When forages were analyzed individually, for every unit increase in forage NDF digestibility in vitro or in situ, DMI and milk production tended to increase by 0.06 and $0.19 \mathrm{~kg} / \mathrm{d}$, respectively, for cows fed CCS; 0.13 and $0.27 \mathrm{~kg} / \mathrm{d}$ for cows fed BMR corn silage; and $0.12 \mathrm{~kg} / \mathrm{d}$ (DMI) for cows fed CSS (there were no changes in milk production for cows fed CSS). Therefore, the present meta-analysis supports the conclusion that lower and similar milk production in cows fed CSS and CCS diets, respectively, than those fed BMRSS diets would be associated with differences in energy intake by cows on BMRSS diets. However, it is important to recognize that results could differ in experiments conducted with high-producing dairy cows because the nutritive value of corn silage has been shown to be advantageous over sorghum silage because of its high starch content (Almas et al., 2017).

Differences in milk fat and protein percentages in the present meta-analysis may reflect the effect of carbohydrates on rumen fermentation and microbial protein synthesis. It is likely that the lower fiber degradation 
A

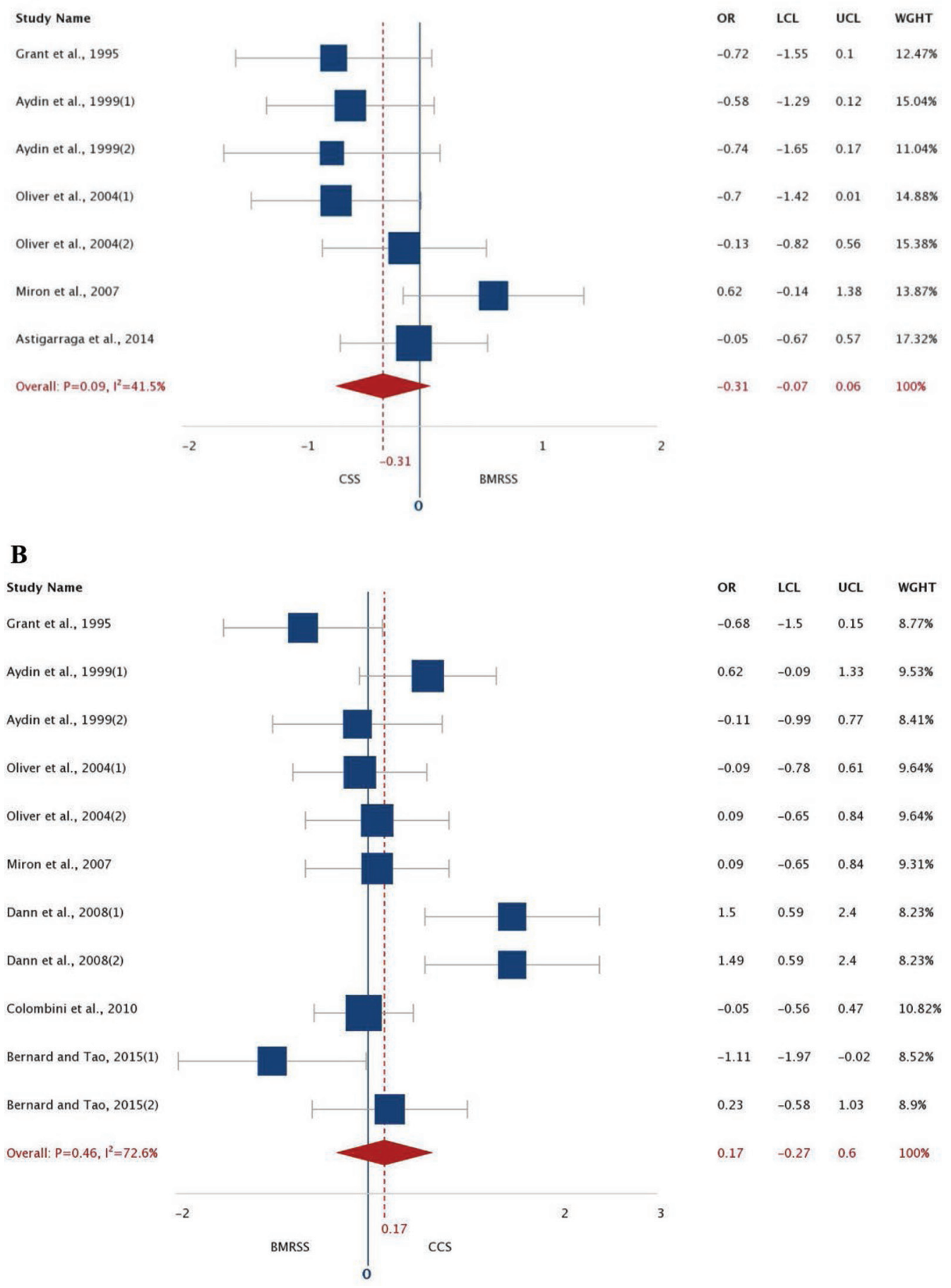

Figure 1. Forest plots of the effect of (A) conventional sorghum silage (CSS) versus brown midrib sorghum silage (BMRSS), and (B) conventional corn silage (CCS) versus BMRSS on DMI in dairy cows. The x-axis shows standardized mean difference (SMD) using the z-statistic. The length of the horizontal lines represents the 95\% CI for the SMD of feeding sorghum silages on DMI and milk production from each study. The size of the square in the center is proportional to the weight assigned to the study, and specific values expressed as percentage are listed in the last column. The vertical solid line represents a mean difference of zero or no effect. Points to the left of the line indicate a decrease in DMI for cows fed CSS compared with BMRSS diets (A), whereas points to the right of the line reveal an increase for cows fed CSS compared with BMRSS diets (B). The diamond on the vertical line at the bottom shows a trend of decreasing DMI for cows fed CSS compared with the BMRSS diet (A) and no effect of silages on DMI between cows fed CCS compared with BMRSS diets $(\mathrm{B})$. OR $=$ odds ratio, LCL $=$ lower confidence limit, UCL $=$ upper confidence limit, WGHT $=$ weight, and $I^{2}$ is a measure of variation beyond chance among studies used in the meta-analysis. Forest plots were generated using DistillerSR Forest Plot Generator from Evidence Partner (https://www.evidencepartners.com/ resources/forest-plot-generator/). 
rate in CSS diets resulted in less ruminal acetate and lower ruminal acetate-to-propionate ratio than cows fed BMRSS diets (Grant et al., 1995). It is possible that the greater digestion of starch in CCS diets, which caused a high proportion of propionate and decreased acetate-to-propionate ratio compared with cows fed BMRSS diets (Dann et al., 2008), affected rumen biohydrogenation and decreased milk fat percentage for cows fed conventional hybrids of sorghum and corn silage hybrids. Moreover, the higher starch concentration of the CCS diets compared with BMRSS diets might have stimulated more microbial protein yield in cows fed CCS diets than the increased fermentable energy provided from greater NDF digestibility for cows fed the BMRSS diets, as demonstrated by Hall and Herejk (2001), which potentially resulted in greater milk protein synthesis. However, those parameters were not measured in this meta-analysis.

Meta-regression analysis demonstrated that parity did not contribute to the heterogeneity of the variables ( $P>0.05$; Supplemental Table S5; https://doi.org/10 $.3168 /$ jds.2018-14552). However, DIM influenced the heterogeneity of DMI in both comparisons and milk production when comparing CCS diets with BMRSS diets $(P=0.01)$. In addition, the inclusion of forage in the diet affected the heterogeneity of milk fat and lactose yields $(P \leq 0.05)$ and influenced the heterogeneity of milk fat concentration $(P=0.08$; Supplemental Table S6; https://doi.org/10.3168/jds.2018-14552). Silage inclusion rate and dietary NDF also affected the heterogeneity of milk lactose yield. Therefore, we suggest that DIM, inclusion of silage and forage in the diet, and dietary NDF should be considered when contrasting the effects of including silages of conventional hybrids of sorghum and corn with BMRSS in future experiments

Despite the limited number of studies, some relevant information for the dairy industry and for future research can be obtained from this meta-analysis. In fact, we were able to confirm the positive advantage of replacing silage of lower digestibility with the lesslignified BMRSS in dairy cow diets. Nonetheless, this meta-analysis should be interpreted carefully because the small sample size may have influenced the outcomes by increasing the margin of error and the power of the statistic, which could limit the generalizability of the findings.

In conclusion, DMI and milk production responded more positively to BMRSS diets than to CSS diets; responses in BMRSS and CCS diets were similar. Milk fat percentage was reduced with any conventional silage type, although milk protein percentage increased in cows with CCS diets. Furthermore, milk fat, protein, and lactose yields were associated with an increase in milk production when cows were fed BMRSS diets compared with CSS diets. The inclusion of silage in the diets and dietary NDF may affect the heterogeneity of milk fat and lactose yields and milk fat concentration. Therefore, those factors, along with the use of highproducing dairy cows, should be considered when planning future lactation experiments comparing BMRSS with conventional silages of sorghum and corn.

\section{ACKNOWLEDGMENTS}

Mention of any trademark or proprietary product in this paper does not constitute a guarantee or warranty of the product by the USDA or the Agricultural Research Service and does not imply its approval to the exclusion of other products that also may be suitable. Research was funded by USDA-ARS Project Number 5090-31000-025-00D.

\section{REFERENCES}

Almas, L. K., B. L. Guerrero, D. G. Lust, H. Fatima, and E. Mensah. 2017. Effect of silage quality on milk production and Ogallala aquifer conservation potential in the Texas High Plains. Southern Agricultural Economics Association (SAEA) 49th Annual Meeting, Mobile, AL. Accessed Apr. 5, 2018. https://ageconsearch.umn .edu/bitstream/252737/2/saea17almas.pdf.

Astigarraga, L., A. Bianco, R. Mello, and D. Montedónico. 2014. Comparison of brown midrib sorghum with conventional sorghum forage for grazing dairy cows. Am. J. Plant Sci. 5:955-962. https:// doi.org/10.4236/ajps.2014.57108.

Aydin, G., R. J. Grant, and J. O'Rear. 1999. Brown midrib sorghum in diets for lactating dairy cows. J. Dairy Sci. 82:2127-2135. https: //doi.org/10.3168/jds.S0022-0302(99)75456-1.

Bean, B., J. Becker, J. Blumenthal, J. Robinson, R. Brandon, R. VanMeter, and D. Pietsch. 2010. Texas Panhandle sorghum hay trial. Texas Cooperative Extension and Texas Agricultural Experimental Extension, College Station. Accessed Sep. 22, 2017. http:// agrilife.org/amarillo/files/2010/11/Hay-Trial-2010-Report.pdf.

Bean, B., and T. McCollum. 2006. Summary of six years of forage sorghum variety trials. Texas Cooperative Extension and Texas Agricultural Experimental Extension, College Station. Accessed Sep. 22, 2017. http://forages.tamu.edu/PDF/Six\%20Year\%20Forage \%20Sorghum\%20Summary.pdf.

Bean, B., T. McCollum, J. Robinson, B. Villareal, R. VanMeter, and D. Pietsch. 2007. Texas Panhandle sorghum hay trial. Texas Cooperative Extension and Texas Agricultural Experimental Extension, College Station. Accessed Sep. 22, 2017. http://agrilife.org/ amarillo/files/2010/11/HayTrial2007.pdf.

Bernard, J. K., and S. Tao. 2015. Short communication: Production response of lactating dairy cows to brachytic forage sorghum silage compared with corn silage from first or second harvest. J. Dairy Sci. 98:8994-9000. https://doi.org/10.3168/jds.2015-9716.

Blum, A., J. Mayer, and G. Golan. 1989. Agronomic and physiological assessments of genotypic variation for drought resistance in sorghum. Aust. J. Agric. Res. 40:49-61. https://doi.org/10.1071/ AR9890049.

Bucholtz, D. L., R. P. Cantrell, J. D. Axtell, and V. L. Lechtenberg. 1980. Lignin biochemistry of normal and brown midrib mutant sorghum. J. Agric. Food Chem. 28:1239-1245. https://doi.org/10 $.1021 /$ jf60232a045.

Colombini, S., L. Rapetti, D. Colombo, G. Galassi, and G. M. Crovetto. 2010. Brown midrib forage sorghum silage for the dairy cow: Nutritive value and comparison with corn silage in the diet. Ital. J. Anim. Sci. 9:e53. https://doi.org/10.4081/ijas.2010.e53. 
Dann, H. M., R. J. Grant, K. W. Cotanch, E. D. Thomas, C. S. Ballard, and R. Rice. 2008. Comparison of brown midrib sorghumsudangrass with corn silage on lactational performance and nutrient digestibility in Holstein dairy cows. J. Dairy Sci. 91:663-672. https://doi.org/10.3168/jds.2007-0521.

Egger, M., D. G. Smith, M. Schneider, and C. Minder. 1997. Bias in meta-analysis detected by a simple, graphical test. BMJ 315:629 634. https://doi.org/10.1136/bmj.315.7109.629.

Grant, R. J., S. G. Haddad, K. J. Moore, and J. F. Pedersen. 1995. Brown midrib sorghum silage for midlactation dairy cows. J. Dairy Sci. 78:1970-1980. https://doi.org/10.3168/jds.S0022 -0302(95)76823-0.

Hall, M. B., and C. Herejk. 2001. Differences in yields of microbial crude protein from in vitro fermentation of carbohydrates. J. Dairy Sci. 84:2486-2493. https://doi.org/10.3168/jds.S0022 -0302(01)74699-1.

Higgins, J. P. T., and S. G. Thompson. 2002. Quantifying heterogeneity in a meta-analysis. Stat. Med. 21:1539-1558. https://doi.org/ $10.1002 / \operatorname{sim} .1186$

Huedo-Medina, T. B., J. Sanchez-Meca, and F. Marin Martinez. 2006 Assessing heterogeneity in meta-analysis: Q statistic or $\mathrm{I}^{2}$ index? Psychol. Methods 11:193-206. https://doi.org/10.1037/1082-989X .11.2.193.

Jahanzad, E., M. Jorat, H. Moghadam, A. Sadeghpour, M.-R. Chaichi, and M. Dashtaki. 2013. Response of a new and a commonly grown forage sorghum cultivar to limited irrigation and planting density. Agric. Water Manage. 117:62-69. https://doi.org/10.1016/j.agwat .2012.11.001.

Jung, H. G., D. R. Mertens, and R. L. Phillips. 2011. Effect of reduced ferulate-mediated lignin/arabinoxylan cross-linking in corn silage on feed intake, digestibility, and milk production. J. Dairy Sci. 94:5124-5137. https://doi.org/10.3168/jds.2011-4495.

Lean, I. J., A. R. Rabiee, T. F. Duffield, and I. R. Dohoo. 2009. Invited review: Use of meta-analysis in animal health and reproduction: Methods and applications. J. Dairy Sci. 92:3545-3565. https://doi .org/10.3168/jds.2009-2140.

Lusk, J. W., P. K. Karau, D. O. Balogu, and L. M. Gourley. 1984. Brown midrib sorghum or corn silage for milk production. J. Dairy Sci. 67:1739-1744. https://doi.org/10.3168/jds.S0022 -0302(84)81499-X

Marsalis, M. A., S. V. Angadi, and F. E. Contreras-Govea. 2010. Dry matter yield and nutritive value of corn, forage sorghum, and BMR forage sorghum at different plant populations and nitrogen rates. Field Crops Res. 116:52-57. https://doi.org/10.1016/j.fcr 2009.11.009.

Mertens, D. R. 2009. Impact of NDF content and digestibility on dairy cows performance. Adv. Dairy Technol. 21:191-201.

Miller, F. R., and J. A. Stroup. 2003. Brown midrib forage sorghum, sudangrass, and corn: What is the potential? Pages $143-151$ in 33rd California Alfalfa \& Forage Symposium. https://alfalfa .ucdavis.edu/+symposium/proceedings/index.aspx?yr $=2003$. Univ. California, Davis.

Miron, J., E. Zuckermanb, G. Adinb, R. Solomonb, E. Shoshanib, M. Nikbachata, E. Yosefa, A. Zenoua, Z. G. Weinberga, Y. Chena, I. Halachmia, and D. Ben-Ghedaliaa. 2007. Comparison of two forage sorghum varieties with corn and the effect of feeding their silages on eating behavior and lactation performance of dairy cows. Anim. Feed Sci. Technol. 139:23-39. https://doi.org/10.1016/j .anifeedsci.2007.01.011.

Miron, J., E. Zuckerman, D. Sadeh, G. Adin, M. Nikbachat, E. Yosef, D. Ben-Ghedalia, A. Carmi, T. Kipnis, and R. Solomon. 2005. Yield, composition and in vitro digestibility of new forage sorghum varieties and their ensilage characteristics. Anim. Feed Sci. Technol. 120:17-32. https://doi.org/10.1016/j.anifeedsci.2005.01.008.

Oba, M., and M. S. Allen. 1999. Evaluation of the importance of the digestibility of neutral detergent fiber from forage: Effects on dry matter intake and milk yield of dairy cows. J. Dairy Sci. 82:589 596. https://doi.org/10.3168/jds.S0022-0302(99)75271-9.

Oliver, A. L., R. J. Grant, J. F. Pedersen, and J. O'Rear. 2004. Comparison of brown midrib- 6 and -18 forage sorghum with conventional sorghum and corn silage in diets of lactating dairy cows. J. Dairy Sci. 87:637-644. https://doi.org/10.3168/jds.S0022 -0302(04)73206-3.

Overton, R. C. 1998. A comparison of fixed-effects and mixed (random effects) models for meta-analysis tests of moderator variable effects. Psychol. Methods 3:354-379. https://doi.org/10.1037/1082 $-989 X .3 .3 .354$

Peacock, J. M. 1982. Response and tolerance of sorghum to temperature stress. Pages 143-159 in Proc. Int. Symp. on Sorghum, Patancheru, India. http://oar.icrisat.org/id/eprint/4050.

R Core Team. 2015. R: A language and environment for statistical computing. R Foundation for Statistical Computing, Vienna, Austria. Accessed Aug. 2, 2017. https://www.R-project.org.

Sousa, D., M. J. VandeHaar, and M. S. Allen. 2016. Increased forage neutral detergent fiber digestibility (in vitro or in situ) is positively related to dry matter intake and milk yield both across and within forage type. J. Anim. Sci. 94(E-Suppl. 5):683-684. (Abstr.)

Sterne, J. A., and R. M. Harbord. 2004. Funnel plots in meta-analysis. Stata J. 4:127-141.

Terrin, N., C. H. Schmid, and J. Lau. 2005. An empirical evaluation of the funnel plot, researchers could not visually identify publication bias. J. Clin. Epidemiol. 58:894-901. https://doi.org/10.1016/ j.jclinepi.2005.01.006.

Viechtbauer, W. 2010. Conducting meta-analyses in R with the metafor package. J. Stat. Softw. 36:1-48. http://www.jstatsoft.org/v36/ i03/. 